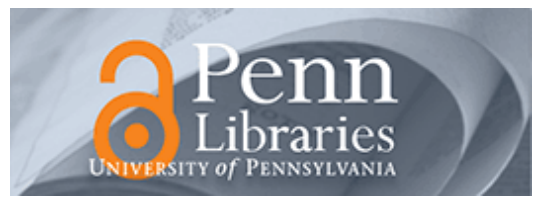

University of Pennsylvania

ScholarlyCommons

Finance Papers

Wharton Faculty Research

2002

\title{
Stocks are Special Too: An Analysis of the Equity Lending Market
}

Christopher C. Geczy

University of Pennsylvania

David K. Musto

University of Pennsylvania

Adam V. Reed

Follow this and additional works at: https://repository.upenn.edu/fnce_papers

Part of the Finance Commons, and the Finance and Financial Management Commons

\section{Recommended Citation}

Geczy, C. C., Musto, D. K., \& Reed, A. V. (2002). Stocks are Special Too: An Analysis of the Equity Lending Market. Journal of Financial Economics, 66 (2-3), 241-269. http://dx.doi.org/10.1016/

S0304-405X(02)00225-8

This paper is posted at ScholarlyCommons. https://repository.upenn.edu/fnce_papers/386

For more information, please contact repository@pobox.upenn.edu. 


\title{
Stocks are Special Too: An Analysis of the Equity Lending Market
}

\author{
Abstract \\ With a year of equity loans by a major lender, we measure the effect of actual short-selling costs and \\ constraints on trading strategies that involve short-selling. We find the loans of initial public offering \\ (IPOs), DotCom, large-cap, growth and low-momentum stocks to be cheap relative to the strategies' \\ documented profits and that investors who can short only stocks that are cheap and easy to borrow can \\ enjoy at least some of the profits of unconstrained investors. Most IPOs are loaned on their first \\ settlement days and throughout their first months, and the underperformance around lockup expiration is \\ significant even for the IPOs that are cheap and easy to borrow. The effect of short-selling frictions \\ appears strongest in merger arbitrage. Acquirers' stock is expensive to borrow, especially when the \\ acquirer is small, though the major influence on trading profits is not through expense but availability. \\ Disciplines \\ Finance | Finance and Financial Management
}




\title{
Stocks are Special Too: An Analysis of the Equity Lending Market
}

\author{
Christopher C. Geczy \\ University of Pennsylvania \\ David K. Musto \\ University of Pennsylvania \\ Adam V. Reed \\ University of North Carolina*
}

This Draft: September 24, 2001

\footnotetext{
* The authors thank Malcolm Baker, Mark Carhart, Domenico Cuoco, Gary Gorton, Don Keim, Jason Segal, Shiv Srinivasan, Rob Stambaugh, an anonymous referee and seminar participants at NYU and the University of North Carolina for helpful comments and advice and Sam Byun, Wes Gray, Victoria Von Krause, and Xiaoting Zhu for outstanding research and computing assistance, and are grateful for financial support from the Q Group and the Rodney L. White Center for Financial Research.
} 


\section{Stocks are Special Too: An Analysis of the Equity Lending Market}

With a year of equity loans by a major lender, we measure the effect of actual shortselling costs and constraints on trading strategies that involve short-selling. We find that wholesale costs of equity loans for shorting IPO's, DotComs, large-cap, growth and lowmomentum stocks are small relative to the documented benefit, and that investors who can short only stocks that are cheap and easy to borrow can closely track the returns of unconstrained investors. Most IPO's are loaned on their first settlement days and throughout their first months, and the underperformance around lockup expiration is significant even for the subset of stocks that are cheap and easy to borrow. The effect of short-selling frictions appears strongest with merger arbitrage. Acquirers' stock is expensive to borrow, especially acquirers with small market capitalizations. The additional cost paid in merger arbitrage positions does not significantly affect profits, but the shortage of available issues reduces profits by more than half. 
The finance literature identifies a number of situations where one asset appears overvalued relative to another, in the sense that an investor apparently profits from shorting the first asset and buying the second, if shorting the first asset is feasible and sufficiently cheap. But it is well known, and acknowledged in the literature, that short positions can be expensive or impossible, and can be involuntarily terminated. So the feasibility and expense of realizing overvaluations through short-selling is an important open question. We address this question with a unique new database that allows us to track the performance of long/short trading strategies subject to the actual short-selling costs and constraints that applied. By the same token, it shows us the revenue that holders of the apparently overvalued assets could have earned by lending, rather than selling, their shares.

The database is a year of equity loans by one of the world's most active lenders. An investor must generally borrow shares he shorted, to give his buyer what she paid for. So the cost, availability and dependability issues related to shorting generally result from the pricing, availability and termination of these equity loans. Our database contains every U.S. equity loan by our data provider from 11/1998 to 10/1999, complete with loan size, pricing and end date. Because the data are daily, they allow us to replicate shortselling strategies subject to actual stock-by-stock short-selling constraints on the correct days. When a strategy calls for shorting a particular stock, we observe directly whether our data provider loaned the stock, and on what terms, so we can judge whether the short sale was feasible, and if so, at what cost. In particular, we can observe the short exposure available to investors who can borrow the expensive-to-borrow stocks, known as "specials," that our data provider loaned, and we observe their borrowing expense, and 
we can also observe the short exposure available to investors who cannot borrow expensive-to-borrow stocks.

After an overview of the relevant regulation and institutional features, we provide summary statistics on our sample loans and then address overvaluation. From the literature we collect several strategies that involve short-selling, then we replicate each strategy at three levels of access to equity loans: one that represents the poor access of a small retail investor by assuming that specials are unavailable, one that represents the good access of a major institution by assuming that specials are available at wholesale, and one that represents the standard assumptions of the literature by imposing zero costs and constraints. The empirical question is how the returns enjoyed at the first two access levels compare to the returns enjoyed at the third.

Our first strategies come from the factor-pricing literature, which documents high average returns for portfolios short in big stocks and long in small stocks, for portfolios short in growth stocks and long in value stocks, and for portfolios short in lowmomentum stocks and long in high-momentum stocks. We replicate these strategies and in each case find that portfolios constructed entirely of easy-to-borrow stocks track the unconstrained portfolios very closely, that we can reject the hypothesis that the expected return difference between constrained and unconstrained portfolios wipes out the documented profits of the unconstrained portfolios, and that averaging in specials has little effect.

The next strategy we consider is short-selling internet-oriented stocks, i.e. DotComs. Our sample period covers a time when DotComs rose substantially, and traded at prices much higher than shortly before or after. One potential explanation for 
the high prices is that DotComs were difficult or expensive to short. We find, however, that short exposure to the Internet Index of Ofek and Richardson (2001) was available to investors with either poor or good access to equity loans. We do find that the expensiveto-borrow DotComs were generally more sensitive to the index than were other DotComs, but their wholesale cost was small relative to the DotCom fluctuations. Initial Public Offerings (IPO's) raise several questions relevant to equity loans. The most basic is the feasibility of shorting them. We find that investors with good access can short most IPOs at first, but investors without access to specials can short none of them. After about a month, at least a quarter of IPOs are available to investors without access to specials. Wholesale borrowing costs for short-selling IPO's, and therefore lending revenue to those holding IPO's, are around 3\%/year at issuance, and drop in 25 trading days to $1.5 \% /$ year, so they do not come close to offsetting the approximately 5\%/year underperformance of IPO's documented by Loughran and Ritter (1995). We address underperformance also by constructing an index of 6-12 month IPO's (the youngest IPO's in which Loughran and Ritter (1995) document underperformance) and measuring the wholesale borrowing cost of specials, which is only $0.44 \% / y e a r$, and the correlation between the index of all IPO's and the index of borrowable IPO's, which is high, though not as high as in the DotCom case.

We also address the underperformance, documented by several recent papers, around IPO insider-lockup expirations. The pattern is strong and significant in the full sample of IPO's, and also in the subsample of IPO's that can be borrowed with either good or poor access to equity loans. Borrowing costs for these trades are trivial. 
Finally, we investigate the cost and feasibility of capturing the average returns of merger arbitrage. The standard trade (see, e.g., Baker and Savosoglu (2001)), is to buy the target and short the acquirer. We find that the incidence of share loans of the acquirer by our data provider is generally low, and that merger arbitrage profits are greatly reduced - though still large - in our sample period when investors can borrow only when our data provider lends. The expense of borrowing an acquirer increases as the market capitalization of the acquirer decreases, but the effect on profitability of the strategy is small relative to the effect of not being able to borrow at all.

The rest of the paper is in six sections. Section I gives some background and describes our data, Section II covers factor portfolios, Section III covers DotComs, Section IV covers IPO's, Section V covers merger arbitrage, and Section VI concludes.

\section{Background and Data Description}

\section{I.A Overview of Equity Loans and the Data}

An equity loan is a temporary swap of ownership. The equity lender transfers legal ownership of a block of shares to the borrower, who simultaneously transfers collateral. Collateral is almost always cash, and the standard collateral for U.S. equities is $102 \%$ of the shares' value. At the loan origination the parties negotiate a rebate rate, which is the amount of interest on the collateral that the lender will rebate to the borrower. Most loans are on a continuing basis, which means they are subject to renegotiation, and to termination by either party, every day. Term loans, which are not subject to renegotiation until a specific future date, are also available. 
Under Regulation $\mathrm{T}$, the permitted purposes for equity loans are facilitating short sales and covering failed deliveries (12 CFR 220.10(a)). U.S. equity transactions settle $t+3$, which means that if an investor short sells equities on trading day $t$ and does not cover by the close of trading then shares must be delivered to his counterparty on trading day $t+3$. Equity loans settle $t+0$, so the standard way to acquire the needed shares is to borrow them on $t+3$. Similarly, if an investor buys on $t$ but his counterparty is unable or unwilling to deliver shares, he can receive shares anyhow through an equity loan on $t+3$.

Equity loans are intermediated by brokers. If an investor wants to short $n$ shares of a hard-to-borrow stock, the investor's broker generally must have a locate on $n$ shares. This means that the broker has contacted an equity lender who agrees (though does not commit) to loan $n$ shares three days later. ${ }^{1}$ The set of potential lenders is large and loosely organized, so there can be an opportunity cost to locating shares which a broker may not wish to expend on small orders or customers.

Our data provider is a custodian bank, acting as a lending agent for its custodial clients (mutual funds, pension funds, etc.). Its borrowers are generally, if not always, broker/dealers borrowing shares as required by short sales or delivery problems. Our database is the terms of every equity loan that was outstanding on any day from November 1998 through October 1999 (the "sample period"), a total of 249 trading days in the equity-loan market. For every day of every loan we have the number of shares and the current rebate rate. There are 273,225 separate loans, with a median duration of three trading days, and 7144 different stocks appear at least once. On an average day, loans of 3170 stocks are outstanding.

\footnotetext{
${ }^{1}$ During our sample period, a locate was required when the stock the customer wished to short was not on the broker's easy-to-borrow list (NASD rule 3370). In 2000 the rule was amended so that the stock had to be on the hard-to-borrow list.
} 
The database does not distinguish continuing and term loans, but we were advised that very few of the loans are term. Accordingly, we assume that all loans are continuing, which allows us to interpret the rebate of a given loan on a given day as the rebate that would have been negotiated for a loan originated that day, even if the loan was not originated that day.

\section{I.B Related Literature}

The sections of this paper describe several causes of expensive borrowing in the equity lending market: initial public offerings, merger arbitrage strategies, and fundamental stock characteristics. Each section discusses literature specific its topic, and this section describes the literature relevant to equity lending in general. Since equity loans and short selling are tightly linked, the short-selling literature is closely related to this work. However, this paper is fundamentally different. We address the availability and pricing of equity loans, while most of the extant short-selling is concerned with their aggregate quantity. The study most similar to ours is that of Krishnamurthy (2001), who replicates the New Bond/Old Bond Treasury-market arbitrage subject to the actual cost of borrowing the New Bond.

The literature has identified several explanations for the quantity of short-sales. MacDonald and Baron (1973) show that stocks with more idiosyncratic risk have higher short interest. Brent, Morse, and Stice (1990) find that stocks with traded options, convertible securities or high betas tend to have high short interest. In addition, as evidence of strategies using short-selling for tax purposes, they find that short interest

follows a seasonal pattern. Gintschell (2000) documents an association between short 
interest on the NASDAQ stocks and the stocks' float. Dechow, Hutton, Meulbroek, and Sloan (2000) find stocks with low ratios of accounting performance measures to market value tend to have higher short interest. An increase short interest around the issuance of seasoned equity offerings is documented in Safieddine and Wilhelm (1996). Richardson (2000) finds no increase in the short interest of high accrual firms even though high accruals predict future underperformance.

In contrast to explaining the causes of short selling, a set of papers has examined the consequences of short-selling. The effect of short selling on stock prices has been examined in papers dating back to Seneca (1967) where high aggregate short interest is shown to be associated with lower returns for the S\&P 500. Similarly, Figlewski (1981) finds that short interest is negatively correlated with future excess returns. Asquith and Meulbroek (1996) find that a portfolio of firms with high short interest underperforms the market over short and long horizons. In the very short-run, Senchack and Starks (1993) find an intra-daily decrease in stock prices after the announcement of higher than expected short interest. Using NASDAQ short interest, Desai, Thiagarajan, Ramesh, and Balachandran (2000) find similar results, and they find an increase in the probability of delisting for firms with high short interest.

Short sale constraints have also generated a long history of theoretical research. Miller (1977) and Figlewski (1981) both hypothesize that short-sale constraints lead to upward biases in stock prices as pessimistic investors are restricted from short-selling. Diamond and Verrecchia (1987)'s rational expectations model shows that stock prices won't be biased if market participants know that short-selling is restricted, but informational efficiency will be reduced. In a model where some investors' information 
is hidden, Hong and Stein (2001) show that large price movements and left-skewness can be a result of short-sale constraints. Two recent papers, D'Avolio (2001) and Duffie, Garleanu and Pedersen (2001), describe the equity lending market theoretically.

Several recent papers use data from the equity-loan market. Reed (2001) uses the equity-lending database used here measure the impact of costly short-selling on the informational efficiency of stock prices. The paper verifies Diamond and Verrecchia (1987)'s hypothesis that short-sale restrictions lead to stock price distributions with larger absolute values and more left-skewness as information is announced. Ofek and Richardson (2001) demonstrate that rebates are generally lower for internet stocks in early 2000, Mitchell, Pulvino and Stafford (2001) show extremely low rebates for stocks in equity carve-out transactions, and D'Avolio (2001) relates the cross section of end-ofmonth specialness to a variety of stock-specific characteristics. Jones and Lamont (2001) show that specials had relatively low future returns in the years around the 1929 crash.

\section{I.C Specialness}

In the Repo market there is a General Collateral, or GC, market rebate rate for bonds that are not scarce (e.g. Duffie (1996)). A bond is on special if its market rebate is below the GC rate, and the shortfall is its specialness. The same terminology and measurement applies in the equity market, so we can determine which stocks are on special, and their specialness, from our rebate data. But in order to infer market specialness from the loans in the database, we must first identify and remove the transaction-specific effect of our data provider's volume discounting. Specifically, our data provider sorts all loans by 
dollar amount into Large, Medium and Small, ${ }^{2}$ then prices Large loans relative to a Large GC rate, Medium loans relative to a Medium GC rate, and Small loans on a case-by-case basis. So to determine a stock's market specialness we must first determine the Large and Medium GC rates for each day, and then compare the rebates for Large and Medium loans to their respective GC rates. Small loans by our data provider are not usable for determining market specialness because there is no benchmark Small GC rate. ${ }^{3}$

Because few stocks are special on a given day, the GC rate for a given loan size and day is easily apparent as the mode for that size and day. For each day, we calculate the mode rebate for Large loans and for Medium loans, and count the number of loans at, below and above their respective modes. The results, in Table I, show $98 \%$ and $76 \%$ of Large and Medium loans, respectively, at their modes. We define the Large and Medium GC rebates to be these modes. They are very close to standard overnight market rates; the Large GC rate is 8bp below the Federal Funds Effective Rate, on average, and the Medium GC rate is $15 \mathrm{bp}$ below.

There are often several loans of a given stock on a given day, and these loans may impute different amounts of specialness. To arrive at a single specialness number, we calculate the specialness of each loan, i.e. the GC rate for the loan's size minus the loan's rebate rate, ${ }^{4}$ and take the value-weighted average across the loans. We define a stock to

\footnotetext{
2 The dollar-value breakpoints between loan sizes are proprietary.

${ }^{3}$ Also, our data provider imputes transaction-specific considerations, such as the dollar value of other loans to that borrower that day, into the rebate of a Small loan. This makes their rebates less representative of the rebate another borrower would receive.

${ }^{4}$ For some loans the collateral is not cash but other securities. In these cases there is a lending fee, not a rebate. If the lending fee is $f b p$ we estimate the specialness to be $f-20 \mathrm{bp}$. This is because we estimate the market rate for overnight loans to our data provider to be around 10bp above Fed Funds, which means that the opportunity cost of getting the GC rate on an overnight loan to our data provider is about 20bp (i.e. Fed Funds $+10 \mathrm{bp}-$ [Fed Funds -8 to $15 \mathrm{bp}]$ ), and so a lending fee of $20 \mathrm{bp}$ corresponds to a GC cash-collateral loan.
} 
be on special on a given day if its specialness on that day is observable and less than $25 \mathrm{bp} .{ }^{5}$ Interest rebates, and therefore specialness costs, are calculated on an interestbearing basis, so for example if an investor borrows $\$ 1 \mathrm{MM}$ of stock with a specialness of $250 \mathrm{bp}$ for 7 calendar days, the specialness cost (with $102 \%$ collateral) is

$(\$ 1.02 \mathrm{MM})(0.025)(7 / 360)=\$ 496$. This should be interpreted as a wholesale, lowerbound cost, since the broker/dealer borrowing from our data provider is free to charge his short-selling customer a mark-up. By the same token, it is an upper bound on the hypothecating revenue earned by the beneficial owner of the shares, i.e. the custodial client whose portfolio the shares came from, since the lending agent makes money.

\section{I.D Estimating Short-Sale Constraints from the Database}

The major empirical question we address with the measurements of market specialness is how they affect the returns to trading strategies that involve short selling. We do this by calculating trading-strategy returns at three levels of access to equity loans, making the usual assumption that all transactions are at the market close. Short selling at the close of day $t$ necessitates an equity loan on day $t+3$, so an investor needs to borrow on $t+3$ to earn -1 times a stock's $t+1$ return. This means that the short-selling time series we can create lag our sample period by two trading days, i.e. from the 10/28/98-10/29/98 return through to the 10/26/99-10/27/99 return. The three access levels are Unconstrained, which allows shorting of any stock at no cost, GC Only, which allows borrowing only of GC stocks, and GC+Specials, which allows borrowing of specials as well, for which the specialness cost must be paid.

\footnotetext{
${ }^{5}$ See Reed (2001) for a discussion of different cutoffs.
} 
The GC Only access level approximates the situation of a small retail investor by assuming zero access to any stock we do not observe to be GC. A GC Only investor can short a stock on $t$, and therefore to earn -1 times its $\mathrm{t}+1$ return, if and only if our data provider had a Medium or Large loan outstanding on $t+3$, and specialness was below 25bp. Because a GC Only investor cannot short specials, his specialness cost is zero.

The next level, representing good access, is $G C \&$ Specials. Investors at this level can short a stock on $t$ if it is observed to be either GC or Special on $t+3$. If it is on special, the investor pays the specialness cost. Since our rebates are wholesale, the costs we calculate represent a zero mark-up and therefore best represent the costs of the largest, best-situated investors (e.g. large hedge funds). Similarly, the assumption that a $G C \&$ Specials investor can borrow all our data provider's specials is also appropriate only for major operators.

Both the GC Only and GC\&Specials access levels are conservative in that they represent access to only one lender. If our data provider does not loan a stock, or makes only Small loans, we assume that the stock cannot be borrowed. To gauge the availability of stocks not loaned by our data provider, we can compare the list of its loaned issues as of December 31, 1998 with the list of issues loaned that day by another lender, Dimensional Fund Advisors (DFA). On that day, our data provider had loans (of any size) of 3289 issues, and DFA had loans of 499 issues. Of the 499 DFA issues, 334 were also loaned by our data provider, but 165 were not. So these 165 were in the borrowable universe but we do not let GC Only and GC+Specials investors borrow them that day. We are also conservative with respect to "recall risk," the risk of a short sale being involuntarily terminated by the lender, by terminating short sales when our data 
provider ceases to have a Medium or a Large loan outstanding, since we do not know who terminated the loans in our database and we do not know if the short could have been extended by a new loan elsewhere.

\section{Factor Portfolios}

Are the factor portfolios of the performance-evaluation literature feasible? That is, can investors actually realize the returns of these long-short portfolios? D' Avolio (2001) shows that growth and low-momentum stocks are relatively more likely to be on special, raising the possibility that the book-to-market strategy of Fama and French (1992) and the Momentum strategy of Jegadeesh and Titman (1993) involve prohibitive specialness costs. But specialness is rare, so the incidence of specialness could still be low relative to the documented profits, and the more numerous GC stocks could be sufficient for tracking the strategies closely. We can address this issue by forming the portfolios available at the Unconstrained access level, which correspond to the portfolios in the literature, then forming the portfolios available at the GC\&Specials and GC Only levels, and finally comparing. The relevant questions are how closely to the constrained portfolios track the unconstrained portfolios, how much extra the GC\&Specials investor must pay for the specials, and whether the difference in expected profit between the constrained and unconstrained portfolios could outstrip the documented profit.

Portfolio assignments for each trading day are calculated first, without regard to short-selling constraints. Assignments follow the literature's conventions, particularly those in Carhart (1997), and are recalculated each Wednesday (or the first trading day thereafter). All breakpoints are calculated with NYSE stocks only. Stocks in the bottom $30 \%$ of capitalizations are assigned to $S M A L L$, and stocks in the top $30 \%$ to $B I G$. Stocks 
in the top $30 \%$ of book-to-market ratios go to HIBM, and stocks in the bottom $30 \%$ to LOBM. Stocks in the top 30\% of returns from 28 to 2 weeks before are assigned to WIN, and stocks in the bottom $30 \%$ to LOSE. The day $t$ returns of the long portfolios $S M A L L_{t}, H I B M_{t}$ and $W_{I N}$ - and of the Unconstrained short portfolios - BIG $G_{U, t}, L O B M_{U, t}$ and $L O S E_{U, t}$ - are the equal-weighted returns of stocks assigned to them for $t$. The day $t$ returns of the $G C \&$ Specials and $G C$ Only short portfolios $B I G_{G S, t}, L O B M_{G S, t}, L O S E_{G S, t}$ and $B I G_{G, t}, L O B M_{G, t}, L O S E_{G, t}$, respectively, are the equal weighted returns of the GC\&Special and GC, respectively, stocks that are assigned to them for $t$. The specialness cost of the $G C \&$ Specials portfolio is calculated separately.

The initial questions are how large the specialness costs of the GC\&Specials portfolios are relative to the documented excess returns of these strategies, and how well the GC\&Specials and GC Only long-short portfolios track their Unconstrained counterparts. The answer to the first question is simple; specialness costs are trivial relative to the documented excess returns. Carhart (1997) reports monthly excess returns of $0.29 \%, 0.46 \%$ and $0.82 \%$ for SMB, HML and PR1YR, respectively; the monthly specialness costs to a $G C \&$ Specials investor of BIG, LOBM and LOSE are $0.003 \%$, $0.022 \%$ and $0.020 \%$, respectively. So it does not appear that specialness costs offset a meaningful portion of the excess returns. ${ }^{6}$ The second question is addressed via simple regressions; results are in Table II.

\footnotetext{
${ }^{6}$ The long-short investor, particularly the investor in SMB, could also benefit from lending the long side. The DFA prospectus dated 4/1/01 reports $16 \mathrm{bp}, 6 \mathrm{bp}$ and $1 \mathrm{bp}$ of securities-lending income earned in 2000 by the U.S. Micro Cap Portfolio (formerly named the U.S. 9-10 Small Company Portfolio; see Keim (1999) for a description), U.S. Small Cap Value Portfolio and U.S. Large Cap Value Portfolios, respectively, and the Vanguard U.S. Stock Index Funds 1999 Annual Report reports approximately 14bp and 3.5bp earned by the Extended Market and Small-Cap Value Index Funds, respectively, in 1999 (to approximate, we divide "Security Lending" income by the average of the respective funds' 12/31/98 and 12/31/99 assets).
} 
Table II makes two main points. First, the GC Only portfolios track their unconstrained versions closely, with $\mathrm{R}^{2}$, s of $95-100 \%$. Note that this is without any particular effort to track the unconstrained version, such as matching industry weights, but rather just buying the equal-weighted index of what's available. Slopes are close to one, and intercepts are small and insignificantly different from zero. Second, the effect of averaging in specials is negligible.

The final question is whether the difference in expected monthly profits between the GC Only and Unconstrained could wipe out the documented profits. To find out, we construct monthly profit series of both portfolios and refer to the empirical distribution of the difference. The portfolio defined as $\left(H I B M-L O B M_{G}\right)-\left(H I B M-L O B M_{U}\right)$ has an average monthly profit of $-2 \mathrm{bp}$ with a standard error of $21 \mathrm{bp}$; against the null hypothesis that the mean is below $-46 b p$ the t-statistic (11 degrees of freedom) is 2.14 , significantly positive with a p-value of $2.8 \%$. Repeating for $\left(W I N-L O S E_{G}\right)-\left(W I N-L O S E_{U}\right)$ we find a monthly mean and standard error of $27 \mathrm{bp}$ and $28 \mathrm{bp}$, respectively, implying a t-statistic of 3.89 , with p-value $0.1 \%$, rejecting the null hypothesis that the mean is below $-82 \mathrm{bp}$. And for $\left(S M A L L-B I G_{G}\right)-\left(S M A L L-B I G_{U}\right)$, the mean and standard error are $2 \mathrm{bp}$ and $3 \mathrm{bp}$, respectively, putting $-29 \mathrm{bp}$ far outside any standard confidence interval. So if expected profits are constant, then loan scarcity and specialness costs are not a barrier to earning profits with these strategies.

The GC Only results indicate that while the factor portfolios are not strictly feasible, they are very close to portfolios that are feasible, even for investors who cannot short scarce stocks. The small cost of averaging in the specials that our data provider loaned, and their small effect on tracking, is consistent with the generally low incidence of 
specialness. Specials may be over-represented among growth and loser stocks, but they are too scarce to interfere with these strategies.

\section{DotComs}

Internet-based companies traded at very high valuations, relative to a couple years before or after, from the late 1990s to early 2000. Why did their markets clear at such high prices? One potential contributing factor, noted by Ofek and Richardson (2001) (OR), is that these stocks, also known as "DotComs," were difficult or prohibitively expensive to sell short. We can address this argument by comparing the returns available to GC Only and GC\&Specials investors to the Unconstrained return. The empirical question is not who makes more money - we already know that DotComs went up over $200 \%$ in our sample period - but instead how closely the constrained returns track the unconstrained version, and how much the $G C \&$ Specials investor must pay. This tells us whether equity-loan frictions were a significant barrier to short exposure to DotComs in our sample period, when they were on their way up.

To structure our empirical tests we need to define the trading strategy of the Unconstrained investor. For simplicity, and also for direct comparison to the existing literature, we define it as the equal-weighted Internet index in OR. That is, we start with the list of DotCom stocks used by $\mathrm{OR}^{7}$ (see that paper for a description), and we assume that the investor wants to short an equal-weighted portfolio of as many stocks on the list as possible. Therefore, the return of the Unconstrained investor corresponds (negatively) to the "Internet index" in Figure 1A of OR. GC Only and GC\&Specials investors short equal-weighted portfolios of all GC and all GC and Special stocks, respectively.

\footnotetext{
${ }^{7}$ Thanks to Matt Richardson for providing the list.
} 
To keep the comparison with OR and others simple, we discuss the results in terms of long portfolios, so the Unconstrained, GC Only and GC\&Specials portfolios are simply equal-weighted portfolios of all, GC, and GC\&Special stocks, respectively. The specialness cost of the GC\&Special portfolios is calculated separately and not added to the return series. In Table III we quantify the relations between the time series with simple regressions. In Panel A we regress the GC\&Specials and $G C$ Only returns on the Unconstrained returns, finding high $\mathrm{R}^{2}$ 's (96\% and 90\%, respectively), insignificant intercepts, and a higher slope for GC\&Specials than for GC Only. Both constrained portfolios track the unconstrained portfolio closely, but the portfolio with specials moves more than 1 for 1 with the unconstrained portfolio, whereas the portfolio with easy-toborrow stocks varies almost exactly 1 for 1 . In Panel B we calculate and compare longshort portfolio returns, long in the NASDAQ and short in DotComs; results are similar.

The specialness cost of the GC\&Specials portfolio, summed over the entire year, is $1.15 \%$. We cannot know how $1.15 \%$ compares to the expected returns of the investors of the time, but it is orders of magnitude smaller than the large positive returns of DotComs in our sample period, and the large negative returns later on.

Our data show that substantial short exposure to DotComs was available even to investors incapable of shorting hard-to-borrow stocks, but they also show that the hardto-borrow DotComs offered investors relatively more exposure. In addition, we find that wholesale borrowing costs were small relative to the realized returns. This evidence from a year of the DotCom episode indicates that equity-loan shortages were a minor impediment to trading on the belief that DotComs were overvalued. 


\section{Initial Public Offerings}

The shortability questions raised by Initial Public Offerings, IPOs, are similar to those of DotComs. Historically, IPOs have significantly underperformed a variety of benchmarks from half a year to five years post-IPO (Loughran and Ritter (1995)), indicating that shorting IPOs and buying the benchmarks over this period is a profitable trading strategy. But since IPOs are generally regarded as hard to short, the feasibility of this strategy is an open question. As with the DotComs, we can gauge the feasibility by comparing IPO indices with the different levels of equity-loan access, measuring the goodness-of-fit and wholesale specialness cost. The wholesale specialness cost is also informative about the lending revenue that a long-term IPO investor could enjoy, offsetting losses to underperformance.

In addition to the long-term trade, the literature also indicates a short-term trade in the days around lockup expirations. Underwriting contracts generally oblige insiders not to sell their shares until a future lockup-expiration date, usually 180 days post-IPO. Several recent studies ${ }^{8}$ document a significantly negative market-excess return in the days around lockup expiration, so abstracting from execution quality and shorting constraints, shorting IPOs and buying the market across lockup expiration has been profitable. Ofek and Richardson (2000) and Field and Hanka (2001) show that paying the bid/ask spread would eliminate much, or all, of the profit, so execution quality is crucial. How crucial is the cost and availability equity loans? We can answer this question for our sample period by simulating the trade, at closing prices, at our three levels of access.

\footnotetext{
${ }^{8}$ Field and Hanka (2001), Keasler (2001), Ofek and Richardson (2000), Brav and Gompers (2001) and Bradley et al. (2001).
} 
Before addressing either the long-term or short-term trades we first establish the actual difficulty of shorting IPOs, subject the usual caveat that we observe the market specialness of only those stocks our data provider loans. Of particular interest is the cross section of specialness in the first month, which features price support for weaker issues, and tight lending restrictions for all issues.

For this study we construct a panel of all IPOs from November, 1997 through October 1999. Following the standard practice of the IPO literature, we eliminate all non-U.S., unit and closed-end offerings, leaving 853 offerings. For each we have the number of shares offered (including the overallotment, if any), the offering price and the offering and lockup expiration dates, compiled from Bloomberg, ipo.com, SDC and the Edgar database of SEC filings.

\section{IV.A Borrowing IPOs in the First Month}

An IPO's first month is qualitatively different, with regard to equity-lending, from the months following. Lendable supply is constrained by the regulation forbidding purchases on margin in the first thirty days, which means brokers cannot lend to customers from other customers' margin accounts. Also, members of the underwriting syndicate are generally obliged not to lend in the first thirty days. Shorting demand may

also be different, due to price support. Lead underwriters attempt to prop up the prices of weak offerings until about a month post-IPO, then they stop (Ellis, Michaely and O'Hara (2000), Aggarwal (2000)). Investors may associate this practice with temporarily inflated prices, and consequently sell short. 
To examine the market for IPO shares in the first month, we assemble the 311 IPOs that are covered by our sample period for their first 25 trading days, a few trading days more than one month. For an overview, Figure 2 shows the breakdown on each trading day into the four major categories: Not Loaned, Small Only, On Special and GC. The IPOs available to a GC Only investor grow steadily from none to a quarter of the sample, while the fraction of IPOs loaned by our data provider starts at three quarters, and shrinks somewhat in the last week. So investors with access to specials can short most IPOs as soon as the first day, but investors without that access are initially incapable of shorting any IPOs, and only gradually gain access to a few. The shrinkage at the end of the 25 trading days is consistent with the diminished role of custodian banks such as our data provider after thirty days, when loans from margin accounts and syndicate members become available.

Figure 1 shows cross sectional variation in the expense of borrowing IPOs. We address this variation with a cross sectional regression of specialness on some intuitive factors. But first, we address the potential for selection bias in the observable sample. An IPO is selected for the observable sample by a Medium or Large loan, an event that is presumably more likely for larger offerings, which are presumably less scarce. An interaction between selection and scarcity could produce a specification error of the sort addressed by Heckman $(1976,1979)$. Figure 2, a histogram of offerings by offer size, locates the unobservable offerings in the smallest size bins. So selection interacts with issue size, which promotes the two-stage "Heckit" selection-correction model. The first stage is a probit model explaining selection with issue size, and the second stage is OLS 
combining the explanatory variables with the Inverse Mills Ratio (commonly denoted ?) from the probit.

The dependent variable is the day $t$ specialness of IPO $i$. The explanatory variables are six intuitive measures of supply and shorting demand. We have the log of the initial supply of IPO $i, L S I Z E_{i}$, and the log-relative return from the offering price to trading day $t, L R E T_{i, t} . L S I Z E_{i}$ is also the explanatory variable in the first-stage probit. To flag DotComs we include $D O T_{i}$, which is 1 for IPOs on the OR list of DotComs, and 0 otherwise, and to represent the benchmark index return we include $\operatorname{LINDX} X_{i, t}$, which is the log-relative return from the close before the first day of trading to the close of $t$ of the appropriate index: the DotCom index of OR for the DotComs, and the CRSP valueweighted index for the others. The log of day- $t$ share turnover, share volume (plus one) divided by IPO shares, is $L T U R N_{i, t}$. Finally, to indicate price support situations, we include $D O G_{i, t}$, which is 1 if the closing price on day $t$ is at or below the offering price, and 0 otherwise. Second-stage results for several event days ${ }^{9}$ are in Panel A of Table IV.

All regressors except the benchmark index enter significantly on at least three of the six days. Smaller issues are more expensive, as are DotComs. Performance enters non-monotonically; specialness generally increases with performance, but conditional on that, price-support issues are more expensive. Specialness also increases with turnover.

The issue-size result is intuitive, and justifies the Heckit approach. The premium for DotComs shows that the observation in OR that DotComs have lower rebates than the general population is robust to all the controls in our regression. Turnover may pick up a positive relation between demand for transactions in general and for short-selling in

\footnotetext{
${ }^{9}$ First-stage Probit results available on request. We also fit Probit models with the other independent variables from the second stage as additional explanatory variables, but they did not enter.
} 
particular, or it may instead identify stocks that are harder to lend because their ownership keeps changing. The positive relation between specialness and return on the offering price supports the heterogeneous-beliefs analysis of Miller (1977), which controlling for offering size, as we do - associates greater underpricing with greater dispersion of investors' valuations, because it implies a bigger right tail of valuations. This implies a bigger left tail, and therefore a more intense desire to sell short. Finally, the extra cost of borrowing the weakest offerings supports the view that price support encourages shorting.

Panel B uses the same data to gauge the revenue from specialness that an IPO investor earns in the first month. The first row contains the average specialness of the available observations on that trading day. So for example, the average specialness across the 226 specialness observations on day 1 is $295 \mathrm{bp}$. The second row includes the estimated specialness of the unobserved observations, where the estimator is the regression model above. We include the second number to address the selection bias noted above. On day 1, the average across the 226 observations and the 85 estimates is 296bp, almost the same, though on later days the disparity is wider. By either measure, the average specialness in days 1 through 20 is in the neighborhood of $240 \mathrm{bp} /$ year, or 20bp in a month. Since the IPO underperformance calculated by Loughran and Ritter (1995) (LR) is in excess of 500bp/year, this is one indication that lending income does not offset underperformance.

\section{IV.B Realizing IPO Underperformance}

We get a more direct indication by repeating the methodology of the DotCom section on an IPO index. That is, we calculate the return on an IPO index at the three 
access levels, and measure tracking error and shorting cost. We use an equal-weighted index of IPOs that are 6-12 months old, because the frictions associated with borrowing IPOs should be more apparent in earlier days, and 6-12 months is the earliest period in which LR document underperformance. As with the DotComs, we discuss returns in terms of long positions.

First, we calculate the specialness cost for the $G C+$ Specials investor, which comes to $44 \mathrm{bp} / \mathrm{year}$, far from the $450 \mathrm{bp}$ profit indicated for half a year ${ }^{10}$ in LR. Next, we regress the GC Only and GC\&Specials index returns on the Unconstrained return. Results, in Panel A of Table V, show $\mathrm{R}^{2 \text { 's }}$ around $80 \%$ for both regressions, similar slopes and insignificant intercepts.

The LR portfolio is short in IPOs and long in matched non-IPOs. We approximate this construction with long-short portfolios that are short in the portfolios of Table V, Panel A, and long in matched indices. If the short side has $n$ DotCom IPOs and $m$ other IPOs, then the long side is $n$ times the DotCom index of OR and $m$ times the value-weighted CRSP index, all divided by $(n+m)$. To see how well the constrained long-short portfolios track the unconstrained portfolio, we run the regressions of Table $\mathrm{V}$, Panel A. The results, in Panel B of Table V, show lower $\mathrm{R}^{2}$ 's, in the neighborhood of 4050\%. In general, the available stocks do not track seasoned IPOs as well as they track DotComs.

Finally, to gauge the expected-return difference between the GC Only and Unconstrained long-short portfolios, we again calculate a confidence interval for the mean of the monthly GC Only long-short profits minus the monthly Unconstrained longshort profits. The sample mean is $-44 \mathrm{bp}$ and its standard error is $18 \mathrm{bp}$, so (again

\footnotetext{
${ }^{10}$ In LR, Table III, Panel A, row 2 minus row 1 of the "Second 6 Months" column.
} 
assuming constant expected returns) so the t-statistic for the null hypothesis that the true mean is below $-75 b p$ is $(75-44) / 18=1.72$, which has a $\mathrm{p}$-value ( $\mathrm{t}$-statistic with 11 degrees of freedom) of $5.65 \%$. With this marginal significance, we reject the hypothesis that investors can not get some of the LR underperformance profits using only GC stocks.

If instead we compare the GC\&Specials long-short portfolio to the Unconstrained portfolio we get a mean and standard error of 4bp and 17bp. Subtracting the 44bp/year specialness from the $4 \mathrm{bp} / \mathrm{month}$ mean, we get a mean of $0 \mathrm{bp}$ and standard error of $17 \mathrm{bp}$, which imply a p-value for the null hypothesis of a mean below $-75 \mathrm{bp}$ of $0.06 \%$. So while the confidence intervals are wider for IPOs than for the factor portfolios in Section II, it appears likely that investors, especially investors with good access to equity loans, can realize at least some of the profits documented in IPO returns.

\section{IV.C Lockup Expiration}

It is implausible that specialness costs could offset a meaningful portion of the extensively-documented lockup-expiration return. The specialness that offsets a $1 \%$ profit earned over a week is over $50 \%$. Specialness of that magnitude is extremely rare (see D’Avolio (2001) and Mitchell, Pulvino and Stafford (2001) for some outlier borrowing costs), and the lockup-expiration trades appear to earn more than $1 \%$ (gross of transactions costs) in less than a week. So the interesting empirical question is not whether costs overwhelm the profits, but rather if the abnormal returns are still significant in the subset of stocks that we observe to be GC, or GC\&Special.

We refer to the lockup-expiration day, the first day when insiders can sell their shares, as day 0 . The literature documents abnormal returns in different holding periods 
around the expiration date. We use two: a three-day window from the close of day -2 to the close of day 1 , for which we have 229 IPOs, and a five-day window from the close of day -3 to the close of day 2 , for which we have 226 IPOs. For each IPO, the trade is to short the IPO and buy the appropriate index. As above, the appropriate index is the OR DotCom index for DotComs, and the value-weighted CRSP index for all other stocks. Also as above, availability is determined day-to-day, so an investor closes out both sides of his trade whenever he cannot borrow three days later. Results are in Table VI.

With Unconstrained access, the return is significant in either holding period, and in the neighborhood of previous studies' results. The second row repeats the test for GC\&Specials access, and again finds significance either way. Specialness cost is trivial. Even with GC Only access (third row) the trade is significantly profitable either way. Therefore, we conclude that shorting frictions do not explain the expiration return.

\section{Merger Arbitrage}

Merger arbitrage strategies can generate large profits. In these strategies, shares of acquiring firms are sold short in the expectation that the share prices of acquiring and target firms will converge by the time the merger is effective. Evidence suggests that acquiring firms' shares decline by less than target firms' shares rise (see Jensen and Ruback (1983) or Asquith (1983)). However, merger arbitrage can lock in any profit arising from discrepancies by short-selling shares of the acquiring firm and covering the short loan with shares of the target firm on the date of the merger. Results presented here indicate that even though the cross section of borrowing costs is heavily influenced by the 
specifics of merger arbitrage deals, the increased borrowing costs do not wipe out merger arbitrage profits.

Arbitrage strategies take advantage of the likely convergence of merger the acquirer and target stock prices, but uncertainty about deal terms makes merger arbitrage strategies risky. As discussed in Jindra and Walkling (2001), there is always a substantial risk that a merger will not go through. Furthermore, the terms of the exchange are subject to change before the merger takes place. In particular, the ratio at which equities are exchanged is the key to determining the profitability of an arbitrage opportunity, and the ratio can change or be announced for the first time between the merger announcement date and the effective date.

Furthermore, practical obstacles can reduce merger arbitrage profits. The profitability of a merger arbitrage strategy depends on the ability of the arbitrageur to short-sell and therefore to borrow acquiring firms' stock. As in the case of relative valuation discrepancies (e.g. Lamont and Thaler (2001)), merger acquirers'stock can be difficult to borrow. Since specialness often increases substantially when a stock is a merger acquirer, merger arbitrage profits from raw returns can be substantially more than the profits available in practice. ${ }^{11}$ It is also important to point out that some stocks may not be available for borrowing at all; the inability to borrow shares can reduce the profitability of merger strategies and increase the risk of an arbitrage portfolio.

\footnotetext{
${ }^{11}$ Here's a quote from Mellon Global Securities Lending Market Update Report March 1-12, 1999:

"Adelphia Communication's intention to purchase Century Communications caused Adelphia to trade at a margin of 775 basis [sic] as traders locked in spreads for this cash, stock and debt deal."
} 


\section{V.A The Effect of Merger Arbitrage on Specialness}

To describe the relationship between specialness and potential profits from merger arbitrage, we construct a sample of stock-swap mergers with announcement dates between October 28, 1998 and September 28, 1999 using data from Securities Data Corporation (SDC). This date range allows us to measure specialness from 3 to 23 days after the announcement of a merger for all of the mergers in the sample and it allows us to keep our sample size relatively stable for 20 days after the announcement. After matching with CRSP data, we end up with a sample of 226 mergers over this period. We design an experiment to minimize any forward-looking bias by using only information available on day $\mathrm{t}$ to predict day $\mathrm{t}+3$ specialness. In particular, we include the 27 ex-post unsuccessful mergers in the sample, and we do not include any measure of arbitrage profits that would rely on the rate at which equities are eventually exchanged.

Table VII presents results from the following regression:

$$
\operatorname{Special}_{t+3}^{\mathrm{A}}=\mathrm{a}+\mathrm{b} \ln \left(\mathrm{Mktcap}^{\mathrm{A}}\right)+\mathrm{c} \ln \left(\mathrm{Mktcap}^{\mathrm{T}}\right)+\varepsilon_{\mathrm{t}}
$$

Since the dependent variable is no less than zero, we employ a left-censored regression technique as described in Greene (1993). As above, we use $t+3$ to estimate the specialness a short-seller would actually face if he were to short sell the acquirer's stock on day t. Since merger arbitrage strategies involve trading in both the target and the acquirer, the maximum size of a strategy might be limited by either the long position or the short position ${ }^{12}$. As evidence that arbitrage strategies involving small target firms generate less demand for acquirer's stock, the target firm's market capitalization,

\footnotetext{
12 According to a representative of Mellon's Global Securities Lending Group, when Chase Manhattan, Corp. entered into an agreement to acquire J.P. Morgan via a stock swap, the supply of Chase shares was large enough to satisfy borrowing demand without trading at a premium.
} 
$\ln \left(\right.$ Mktcap $\left.^{\mathrm{T}}\right)$, is positively related to specialness with coefficient of 0.2736 . However, the relationship between specialness and the target's market capitalization is not as important as the relationship between specialness and the acquirer's market capitalization; the pvalue is $11.67 \%$ for the coefficient on $\ln \left(\mathrm{Mktcap}^{\mathrm{T}}\right)$. As expected, the acquirer's capitalization is significantly and negatively related to specialness.

The regression results discussed above are from a cross-sectional regression on the day of the merger announcement. We also run the cross-sectional regression 5, 10, 15 and 20 days after the announcement. More acquiring firms are on special three days after the day of the announcement than later days; 62 firms are on special three days after the announcement, while 44 to 53 firms are on special 8,13, 18 and 23 days after the announcement. Furthermore, the intercept and the coefficient on lnMktcap ${ }^{\mathrm{A}}$ both shrink in magnitude and significance after 5 days. Jensen \& Ruback (1983) summarize evidence indicating merger announcement days are the most profitable days for merger arbitrage strategies, and our evidence supports the hypothesis that demand for borrowing stock is highest on these profitable announcement days.

\section{V.B Merger Arbitrage Portfolios}

As in the previous sections, the other important question is whether merger profits exist after taking equity-loan frictions into account. We form daily long-short portfolio returns, analogously to above, based on announced stock-swap mergers from the SDC database. Daily portfolio returns are equally-weighted averages of as few as 7 or as many as 87 individual merger arbitrage positions. The Unconstrained investor simply shorts all acquirers and buys all targets in mergers that were announced at least two days before 
(the two-day gap avoids announcement effects, and ensures feasibility), and have not ended, putting the same dollar amount on the target and the acquirer. The $G C \&$ Specials investor needs a Medium or Large loan of the acquirer three days later, and the GC Only investor needs the acquirer to be $G C$ three days later.

We do not follow Baker and Savasoglu (2000)'s method of using the exchange ratios of the stock-swap mergers, for two reasons. First, the exchange ratios reported in SDC may not be available to arbitrageurs on the announcement date, and if the ratio changes or is announced after the merger announcement but before the merger is completed or withdrawn, an arbitrage portfolio using the reported exchange ratio would not be feasible. Second, as a practical matter, very few exchange ratios are reported in SDC; using SDC exchange ratios would substantially reduce the sample size. Cumulative profits for an investor who starts with a dollar long and a dollar short on 10/28/98 are in Figure 3.

Figure 3 shows that merger arbitrage profits are large, but they are reduced when borrowing feasibility is taken into account. Table VIII shows cumulative arbitrage portfolio returns are $64.287 \%$ without accounting for short-selling issues. However, when we use only those merger positions where the acquirer's stock shows up in the loan database, $G C \&$ Specials, portfolio returns are reduced to $44.568 \%$. The additional cost from borrowing special acquirer stocks is small; profits are reduced by only $0.256 \%$ when the additional cost of specialness is included in the calculation. Furthermore, if we assume that specials cannot be borrowed, the GC Only portfolio, profits fall to $31.127 \%$. The reduction in cumulative returns, $33.16 \%$, is economically significant, and the 
reduction is statistically significant even though the daily portfolio return differences are small on average, $0.090 \%$.

The GC Only portfolio accounts for short-selling availability and excludes announcement-day returns. Nevertheless, the Sharpe Ratio for the portfolio is well above that of the S\&P 500, 46.318 versus 14.448 . Computing 4-factor alphas from a daily regression, we see that the merger arbitrage strategy performs very well on a riskadjusted basis. The intercept in the Unconstrained regression is equivalent to a $94.733 \%$ annual return, and it is statistically significant. As we saw with the average returns, the difference between the Unconstrained portfolio's alpha and the GC Only portfolio's alpha, $40.227 \%$, is large and the difference is statistically significant. The inability to borrow stocks reduces profits by an economically and statistically significant amount. The risks involved in merger-arbitrage strategies are highlighted by the fact that ex-post unsuccessful merger strategies perform significantly worse than strategies that used only ex-post successful mergers. The cumulative return of the portfolio of successful mergers is $82.505 \%$ while the portfolio of failed mergers has a $-34.764 \%$ cumulative return.

Following the methodology of the IPO and DotCom sections, we can ask how closely the constrained portfolios track the unconstrained portfolio. To answer the question we regress the GC\&Specials portfolio's daily time series on the Unconstrained portfolio's time series. The statistically significant coefficient on the unconstrained portfolio is 0.715 and the $\mathrm{R}^{2}$ is $40.82 \%$. The match is even weaker for the GC Only portfolio; the statistically significant coefficient on the Unconstrained portfolio is 0.534 and the $\mathrm{R}^{2}$ is $31.13 \%$. Even though the constrained portfolios still earn a large, 
significant profit, the correlation between constrained and unconstrained merger arbitrage portfolios is relatively low.

Even if a loan shows up in our database, we can't say the acquirer's stock is available for short selling in general because our database only reflects the wholesale market for borrowing shares. Furthermore, since shares can be borrowed from a number of sources for any short-seller, it would be difficult to obtain estimates on the general level of availability. For this reason, we present results for an even more feasible portfolio, one where merger profits are earned only by a long position in the target's stock, $\mathrm{r}_{\mathrm{i}, \mathrm{t}}=\mathrm{r}_{\mathrm{T}, \mathrm{t}}$. Table VIII shows that the returns to this strategy are better than the returns to the long-short strategy; the strategy earns $99.013 \%$ over the one year period with a Sharpe Ratio of 96.421. Since the long-short portfolio return is computed as $r_{T}-r_{A}$, the fact that the long only portfolio has better returns than the long-short portfolio implies that merger acquirers have positive returns on average. This is consistent with some of the earlier work summarized in Jensen and Ruback (1983). Of course, the long only strategy loses one of the primary benefits of merger arbitrage portfolios; the strategy is not immune to market fluctuations. However, when we compute 4-factor alphas, we see that the long only portfolio still out performs the long-short portfolio on a risk-adjusted basis; the annualized alpha is $157.036 \%$ for the long only portfolio and $94.733 \%$ for the long-short portfolio. The alphas, although statistically significant, rely on one year of daily data; a different time-period could yield a different result. 


\section{Summary and Conclusion}

Short sales generally require equity loans, and the availability and costs of these loans vary across stocks and days. The feasibility and profitability of strategies that involve short selling is therefore an important question that a cross section and time series of equity-loan prices can answer. With a year of equity-loan data from one of the world's most active lenders, we replicate several strategies that involve short selling at three levels of access to loans: access to any stock for free, access to any stock loaned in size by our data provider at the terms we observe, and access only to non-scarce stocks. We briefly summarize the major findings, are consider some implications.

\section{VI.A Factor Portfolios}

The long-short portfolios of the factor-pricing literature are easy to track very closely with only the cheap-to-borrow GC stocks. There may be an expected-return difference, but it is many standard errors from the documented profitability of these strategies. This supports the interpretation, common in the performance-evaluation literature, that the returns of factor portfolios are available to money managers without skill. If short-selling problems explain this availability, they are problems of another variety, such as short-selling prohibitions (as in Hong and Stein (2001)) or liquidity

constraints (as in Shleifer and Vishny (1997)).

\section{VI.B DotComs}

Our results provide little support for the view that short-selling frictions made it hard to bet that DotComs would go back down. Short exposure to DotComs was not 
costly or difficult; a portfolio constructed from only easy-to-borrow stocks tracks an Internet Index closely over our sample period, and the wholesale cost of a portfolio with harder-to-borrow stocks, which tracks even more closely is only $1.15 \%$ for the year. We do find the harder-to-borrow DotComs to have greater loadings on the Internet Index, suggesting that investors with good access to equity loans could get more short exposure per dollar short than could other investors.

\section{VI.C Initial Public Offerings}

Short exposure to IPO's is generally feasible for those with good access to equity loans, even in the first days of trading. The popular press speculates that underwriters boosted first-day returns with prearranged trades at high prices; our evidence that wellplaced investors can generally short all but the smallest offerings on their first days suggests that this would be difficult. Investors with good access to equity loans could have shorted if they thought prices were artificially high. Across IPO's we find an extra cost to shorting hotter offerings, which supports the Miller (1977) heterogeneousinvestors view. We also find, however, that the struggling offerings subject to the price support documented by Aggarwal (2000) and Ellis et al. (2000), are also more expensive, which represents indirect evidence that investors do in fact short offerings they believe to be artificially high. The cost of shorting 6 to 12 month-old IPOs is only $44 \mathrm{bp}$, far short of the underperformance that Loughran and Ritter (1995) document. The trade indicated by the lockup-expiration literature is also significantly profitable with only readily available shares, though access to scarce shares improves the significance considerably. 


\section{VI.D Merger Arbitrage}

The area where we find the greatest reduction in opportunity caused by shortselling costs and constraints is in merger arbitrage. Profits drop substantially when we constrain arbitrageurs to short only those acquirers that our data provider loaned, and they drop substantially again when we constrain to only those acquirers that were easy to borrow. The lesson from our results, combined with those of Lamont and Thaler (2001),

D'Avolio (2001), Mitchell, Pulvino and Stafford (2001) and Reed (2001), is that specialness is a stock-specific, rather than categorical, consideration. Similar to the bond-market results in Krishnamurthy (2001), the equity-market results demonstrate that well-known stock-specific trades, rather than categorical portfolios, can be severely compromised by borrowing problems. As Lamont and Thaler (2001) note, there are other opportunities for short exposure to acquirers, in particular synthetic shorts from the

options market. The simultaneous clearing of the option and equity-loan markets for these stocks is a promising topic for future research. 


\section{Bibliography}

Aggarwal, Reena, 2000, Stabilization Activities by Underwriters after Initial Public Offerings, Journal of Finance 55, 1075-1103

Asquith, Paul, 1983, Merger Bids, Uncertainty, and Shareholder Returns, Journal of Financial Economics 11, 51-83.

Asquith, Paul, and Lisa Meulbroek, 1996, An Empirical Investigation of Short Interest, Working Paper, Harvard Business School.

Baker, Malcolm and Serkan Savasoglu, 2000, Limited Arbitrage In Mergers and Acquisitions, Working Paper, Harvard Business School.

Bradley, Daniel, Bradford Jordan, Ivan Roten and Ha-Chin Yi, 2001, Venture capital and IPO lockup expiration: an empirical analysis, Journal of Financial Research, forthcoming.

Brav, Alon, and Paul A. Gompers, 2001, The role of lockups in initial public offerings, Working Paper, Duke and Harvard Universities.

Brent, Averil, Dale Morse, and E. Kay Stice, 1990, Short Interest: Explanations and Tests, Journal of Financial and Quantitative Analysis 25, 273-289.

Carhart, Mark, 1997, On persistence in mutual fund performance, Journal of Finance, v52, n1, pp. 57-82.

D'Avolio, Gene, 2001, The market for borrowing stock, Harvard University Working Paper.

Dechow, Patricia M., Amy P. Hutton, Lisa Meulbroek, and Richard G. Sloan, 2000, Short-Sellers, Fundamental Analysis and Stock Returns, Forthcoming, Journal of Financial Economics.

Desai, Hemang, S. Ramu Thiagarajan, K. Ramesh, and Balachandran, 2000, An Investigation of the Informational Role of Short Interest in the Nasdaq Market, Working Paper, Southern Methodist University.

Diamond, Douglas W., and Robert E. Verrecchia, 1987, Constraints on Short-Selling and Asset Price Adjustment to Private Information, Journal of Financial Economics 18, 277 311.

Duffie, Darrell, 1996, Special Repo Rates, Journal of Finance 51, 493-526.

Duffie, Darrell, Nicolae Garleanu and Lasse Heje Pedersen, 2001, Securities Lending, Shorting and Pricing, Working Paper, Stanford University. 
Ellis, Katrina, Roni Michaely and Maureen O'Hara, 2000, When the Underwriter is the Market Maker: An Examination of Trading in the IPO Aftermarket, Journal of Finance 55, 1039-1074.

Fama, Eugene, and Kenneth French, 1992, The cross-section of expected stock returns, Journal of Finance 47, 427-465.

Field, Laura C., and Gordon Hanka, 2001, The Expiration of IPO Share Lockups, Journal of Finance, 56(2), pp. 471-500.

Figlewski, Stephen, 1981, The Informational Effects of Restrictions on Short Sales: Some Empirical Evidence, Journal of Financial and Quantitative Analysis 4, 463-476.

Gintschell, Andreas, 2000, Short Interest on NASDAQ, Working Paper, University of Rochester.

Greene, William H., 1993, Econometric Analysis, Second Edition. (Macmillan Publishing Company, New York).

Heckman, James, 1976, The common structure of statistical models of truncation, sample selection, and limited dependent variables and a simple estimator for such models, Annals of Economic and Social Measurement 5, 475-92.

Heckman, James, 1979, Sample selection as a specification error, Econometrica 47, 153 161.

Hong, Harrison and Jeremy Stein, 2001, Differences of Opinion, Rational Arbitrage and Market Crashes, Working Paper, Stanford and Harvard Universities.

Jegadeesh, N., and Sheridan Titman, 1993, Returns to buying winners and selling losers: implications for stock-market efficiency, Journal of Finance 48, 93-130.

Jensen, Michael C., and Richard S. Ruback, 1983, The Market for Corporate Control, Journal of Financial Economics 11, 5-50.

Jindra, Jan and Ralph A. Walkling, 2001, Speculation Spreads and the Market Pricing of Proposed Acquisitions, Working Paper, Ohio State University.

Jones, Charles M., and Owen A. Lamont, 2001, Short Sale Constraints and Stock Returns, Journal of Financial Economics, forthcoming.

Keasler, Terrill R., 2001, Underwriter lock-up releases, initial public offerings and aftermarket performance, Financial Review 37, 1-20. 
Keim, Donald B., 1999, An analysis of mutual fund design: the case of investing in small-cap stocks, Journal of Financial Economics 51, 173-194.

Krishnamurthy, Arvind, 2001, The Bond/Old-Bond Spread, Working Paper, Northwestern University.

Lamont, Owen A. and Richard H. Thaler, 2001, Can the market add and subtract? Mispricing in tech stock carve-outs. Working Paper, The University of Chicago. Loughran, Tim, and Jay R. Ritter, 1995, The new issues puzzle, Journal of Finance 50, 23-51.

MacDonald, John G., and Donald C. Baron, 1973, Risk and Return on Short Positions in Common Stocks, Journal of Finance 28, 97-107.

Miller, Edward M., 1977, Risk, uncertainty and divergence of opinion, Journal of Finance 32, 1151-1168.

Mitchell, Mark, Todd Pulvino and Erik Stafford, 2001, Limited arbitrage in equity markets, Working Paper, Harvard Business School.

Ofek, Eli, and Matthew Richardson, 2000, The IPO lock-up period: implications for market efficiency and downward sloping demand curves, Working Paper, New York University.

Ofek, Eli and Matthew Richardson, 2001, DotCom Mania: A Survey of Market Efficiency in the Internet Sector, Working Paper, New York University.

Reed, Adam V. 2001, Costly Short-Selling and Stock Price Reactions to Earnings Announcements, Working Paper, University of Pennsylvania.

Richardson, Scott, 2000, Accruals and Short Selling: An Opportunity Forgone?, Working Paper, University of Michigan.

Safieddine, Assem, Jr. and William J. Wilhelm, 1996, An Empirical Investigation of Short-Selling Activity Prior to Seasoned Equity Offerings, Journal of Finance 51, 729_ 749.

Senchack, A. J., and Laura T. Starks, 1993, Short-Sale Restrictions and Market Reaction to Short-Interest Announcements, Journal of Financial and Quantitative Analysis 28, 177-194.

Seneca, Joseph J., 1967, Short Interest: Bearish or Bullish?, Journal of Finance 22, 6770.

Shelifer, Andrei and Robert W. Vishny, 1997, The limits of arbitrage, Journal of Finance 52, 35-55. 


\section{Table I \\ Rebate Rates Relative to Mode}

For each trading day from 11/1/1998 through 10/31/1999 we calculate the mode rebate rate of Medium-size loans and of Large-size (as categorized by our data provider) domestic equity loans by our data provider. The table shows, for the two size-categories separately and then for the two combined, the percentage of loans with rebates below, at, and above their respective size-modes for the day.

\begin{tabular}{lllll} 
Loan Size & <Mode & $=$ Mode & > Mode & Total \\
\hline Medium & $21.76 \%$ & $76.10 \%$ & $2.15 \%$ & $29.08 \%$ \\
Large & $1.05 \%$ & $98.30 \%$ & $0.65 \%$ & $70.92 \%$ \\
Medium and Large & $7.07 \%$ & $91.85 \%$ & $1.09 \%$ & $100.00 \%$ \\
\hline
\end{tabular}

Table II

Comparison of Factor Portfolio Returns

For each trading day $t$ from 10/29/1998 through 10/27/1999 we calculate nine long-short portfolio returns to the close of $t$ from the close of $t-1$. The specialness of a stock is the value-weighted average shortfall of the rebate rates of all Medium or Large (as categorized by our data provider) loans of the stock from the Medium or Large mode rebates, respectively. A stock is a special if its specialness is at least $25 \mathrm{bp}$, and is $G C$ if its specialness is lower. Portfolio assignments for each trading day are calculated first, without regard to short-selling constraints. Assignments are recalculated each Wednesday (or the first trading day thereafter). All breakpoints are calculated with NYSE stocks only. Stocks in the bottom 30\% of capitalizations are assigned to SMALL, and stocks in the top 30\% to BIG. Stocks in the top 30\% of bookto-market ratios go to $H I B M$, and stocks in the bottom $30 \%$ to $L O B M$. Stocks in the top $30 \%$ of returns from 28 to 2 weeks before are assigned to WIN, and stocks in the bottom $30 \%$ to LOSE. The day $t$ returns of the long portfolios - SMALL,$H I B M_{t}$ and $W I N_{t}$ - and of the Unconstrained short portfolios - BIG $G_{U, t}$, $L O B M_{U, t}$ and $L O S E_{U, t}$ - are the equal-weighted returns of stocks assigned to them for $t$. The day $t$ returns of the GC\&Specials and GC Only short portfolios $B I G_{G S, t}, L O B M_{G S, t}, L O S E_{G S, t}$ and $B I G_{G, t}, L O B M_{G, t}, L O S E_{G, t}$, respectively, are the equal weighted returns of the GC\&Special and GC, respectively, stocks that are assigned to them for $t$. T-statistics are below coefficients, in parentheses.

\begin{tabular}{|c|c|c|c|c|}
\hline$\left(S M A L L_{t}-B I G_{G S, t}\right)$ & $=$ & $\begin{array}{l}-0.0000 \\
(-0.12)\end{array}$ & $\begin{array}{l}+1.002\left(S M A L L_{t}-B I G_{U, t}\right) \\
(915)\end{array}$ & $\begin{array}{l}\mathrm{R}^{2}=99.97 \% \\
\mathrm{~N}=251\end{array}$ \\
\hline$\left(S M A L L_{t}-B I G_{G, t}\right)$ & $=$ & $\begin{array}{l}0.00001 \\
(0.47)\end{array}$ & $\begin{array}{l}+1.001\left(S M A L L_{t}-B I G_{U, t}\right) \\
(433)\end{array}$ & $\begin{array}{l}\mathrm{R}^{2}=99.87 \% \\
\mathrm{~N}=251\end{array}$ \\
\hline$\left(H I B M_{t}-L O B M_{G S, t}\right)$ & $=$ & $\begin{array}{l}0.00003 \\
(0.45)\end{array}$ & $\begin{array}{l}+1.148\left(H_{I B M}-L O B M_{U, t}\right) \\
(88.0)\end{array}$ & $\begin{array}{l}\mathrm{R}^{2}=96.9 \% \\
\mathrm{~N}=251\end{array}$ \\
\hline$\left(H I B M_{t}-L O B M_{G, t}\right)$ & $=$ & $\begin{array}{l}0.00002 \\
(0.27)\end{array}$ & $\begin{array}{l}+1.115\left(H^{\prime} B M_{t}-L O B M_{U, t}\right) \\
\quad(71.5)\end{array}$ & $\begin{array}{l}\mathrm{R}^{2}=95.4 \% \\
\mathrm{~N}=251\end{array}$ \\
\hline$\left(W I N_{t}-L O S E_{G S, t}\right)$ & $=$ & $\begin{array}{l}0.0003 \\
(2.84)\end{array}$ & $\begin{array}{l}+0.941\left(\text { WIN }_{t}-\operatorname{LOSE}_{U, t}\right) \\
(67.8)\end{array}$ & $\begin{array}{l}\mathrm{R}^{2}=94.9 \% \\
\mathrm{~N}=251\end{array}$ \\
\hline$\left(W_{I N}-L O S E_{G, t}\right)=$ & & $\begin{array}{l}0.0003 \\
(2.49)\end{array}$ & $\begin{array}{l}+0.943\left(W_{I N}-L O S E_{U, t}\right) \\
(67.3)\end{array}$ & $\begin{array}{l}\mathrm{R}^{2}=94.8 \% \\
\mathrm{~N}=251\end{array}$ \\
\hline
\end{tabular}




\section{Table III \\ Comparison of DotCom Index Returns}

For each trading day $t$ from 10/29/1998 through 10/27/1999 we calculate three equal-weighted averages of returns of DotCom stocks (as enumerated by Ofek and Richardson (2001)) to the close of $t$ from the close of $t$ - 1 . The specialness of a stock is the value-weighted average shortfall of the rebate rates of all Medium or Large (as categorized by our data provider) loans of the stock from the Medium or Large mode rebates, respectively. A stock is on special if its specialness is at least $25 \mathrm{bp}$. Unconstrained Un $_{t}$ is the average across all stocks, GC\&Special $t_{\text {is }}$ the average across all stocks with Medium or Large loans on $t+2$, and $G C_{-} O n l y_{t}$ is the average across all stocks that have a Medium or Large loan and that are not on special on $t+2$. Regressions of GC\&Special and GC_Only on Unconstrained are in the Panel A, and regressions of $G C \& S p e c i a l-N A S D$ and $G C \_O n l y-N A S D$ on Unconstrained-NASD, where $N A S D_{t}$ is the Nasdaq index return on day $t$. T-statistics are below coefficients, in parentheses.

\begin{tabular}{|c|c|c|c|}
\hline Panel A: & Total Index Returns & & \\
\hline GC\&Special $t_{t}$ & $\begin{array}{c}=-0.0001 \\
(-0.18)\end{array}$ & $\begin{array}{l}+1.184 \text { Unconstrained }_{t}+e_{t} \\
(81.9)\end{array}$ & $\begin{array}{l}\mathrm{R}^{2}=96.4 \% \\
\mathrm{~N}=251\end{array}$ \\
\hline GC_Only $y_{t}$ & $\begin{array}{l}=-0.0007 \\
(-1.05)\end{array}$ & $\begin{array}{l}+1.020 \text { Unconstrained }_{t}+e_{t} \\
(47.3)\end{array}$ & $\begin{array}{l}\mathrm{R}^{2}=90.0 \% \\
\mathrm{~N}=251\end{array}$ \\
\hline
\end{tabular}

Panel B: $\quad$ Market-Excess Index Returns

\begin{tabular}{llll}
\hline$\left(\right.$ GC\&Special $\left._{t}-N A S D_{t}\right)=-0.0002$ & +1.200 & $\left(\right.$ Unconstrained $\left._{t}-N A S D_{t}\right)+e_{t}$ & $\mathrm{R}^{2}=90.9 \%$ \\
& $(-0.64)$ & $(49.8)$ & $\mathrm{N}=251$ \\
& & & \\
$\left(\right.$ GC_Only $_{t}-$ NASD $\left._{t}\right)$ & $=-0.0003$ & $+0.921\left(\right.$ Unconstrained $\left._{t}-N A S D_{t}\right)+e_{t}$ & $\mathrm{R}^{2}=77.7 \%$ \\
& $(-0.51)$ & $(29.5)$ & $\mathrm{N}=251$
\end{tabular}




\section{Table IV \\ Cost of Borrowing IPOs: Cross Section and Time Series}

We construct a panel of 311 IPOs whose first 25 trading days occurred between 10/28/1998 and 10/26/1999. If our data provider made a Medium or Large (as categorized by our data provider) loan of IPO $s$ on its $t+3^{\text {rd }}$ trading day then its specialness cost for shorting on day $t$ is the value-weighted average shortfall of the rebate rates of all Medium or Large loans of the stock from the Medium or Large mode rebates, respectively, on $t+3$. If there were no such loans then specialness is missing. Panel A reports cross sectional regressions where the dependent variable is the cost (in percent) of shorting IPO $\mathrm{s}$ on its indicated trading day $t, D O T$ is 1 if IPO $s$ is on the DotCom list of Ofek and Richardson (2001), LRET is the logrelative return of the IPO from its offering price to the close of $t, L I N D X$ is the contemporaneous logrelative market return (the Internet Index from Ofek and Richardson (2001) for DotComs, and the valueweighted CRSP index for others), DOG is 1 if the IPO closed at or below its offering price on $t, L S I Z E$ is the log of the offering price of the IPO times the number of shares offered, and $L V O L$ is the log of one plus the number of shares of the IPO traded on $t$, divided by the number of shares sold in the IPO. The Inverse Mills Ratio from running a Probit model for selection to the sample (i.e. whether or not the stock was loaned on t; the explanatory variable is LSIZE) is denoted by ? (i.e. the Heckman (1979) 2-stage procedure). The model is estimated for six values of $t$. T-statistics are below, in italics. At the bottom of each column is the $\mathrm{R}^{2}$ and the number of observations. Panel $\mathrm{B}$ contains average specialness costs for the same days. The first row is the average across the IPOs with non-missing specialness. The second row is across all 311 IPOs, where missing specialness is replaced by estimated specialness using the model of Panel A.

Panel A: $\quad$ Cross-Sectional Regressions

\begin{tabular}{|c|c|c|c|c|c|c|}
\hline & Day 1 & Day 5 & Day 10 & Day 15 & Day 20 & Day 25 \\
\hline Intercept & $\begin{array}{l}4.568 \\
3.42\end{array}$ & $\begin{array}{l}13.401 \\
9.65\end{array}$ & $\begin{array}{l}15.463 \\
6.74\end{array}$ & $\begin{array}{l}12.106 \\
3.86\end{array}$ & $\begin{array}{l}8.869 \\
2.37\end{array}$ & $\begin{array}{l}6.923 \\
0.74\end{array}$ \\
\hline$D O T$ & $\begin{array}{l}0.122 \\
1.58\end{array}$ & $\begin{array}{l}0.207 \\
2.24\end{array}$ & $\begin{array}{l}0.410 \\
2.55\end{array}$ & $\begin{array}{l}0.461 \\
2.23\end{array}$ & $\begin{array}{l}0.423 \\
1.74\end{array}$ & $\begin{array}{l}0.312 \\
1.10\end{array}$ \\
\hline LRET & $\begin{array}{l}0.562 \\
5.50\end{array}$ & $\begin{array}{l}0.467 \\
3.59\end{array}$ & $\begin{array}{l}0.492 \\
2.41\end{array}$ & $\begin{array}{l}0.686 \\
2.60\end{array}$ & $\begin{array}{l}0.217 \\
0.74\end{array}$ & $\begin{array}{l}0.197 \\
0.62\end{array}$ \\
\hline LINDX & $\begin{array}{l}0.188 \\
0.13\end{array}$ & $\begin{array}{l}-0.293 \\
-0.58\end{array}$ & $\begin{array}{l}-0.542 \\
-0.98\end{array}$ & $\begin{array}{l}-0.612 \\
-0.96\end{array}$ & $\begin{array}{l}-0.077 \\
-0.12\end{array}$ & $\begin{array}{l}0.702 \\
1.02\end{array}$ \\
\hline$D O G$ & $\begin{array}{l}0.332 \\
3.10\end{array}$ & $\begin{array}{l}0.288 \\
2.38\end{array}$ & $\begin{array}{l}0.465 \\
2.23\end{array}$ & $\begin{array}{l}0.436 \\
1.66\end{array}$ & $\begin{array}{l}0.185 \\
0.57\end{array}$ & $\begin{array}{l}0.656 \\
1.64\end{array}$ \\
\hline LSIZE & $\begin{array}{l}-0.107 \\
-1.54\end{array}$ & $\begin{array}{l}-0.575 \\
-7.85\end{array}$ & $\begin{array}{l}-0.707 \\
-5.87\end{array}$ & $\begin{array}{l}-0.539 \\
-3.32\end{array}$ & $\begin{array}{l}-0.370 \\
-1.91\end{array}$ & $\begin{array}{l}-0.250 \\
-0.55\end{array}$ \\
\hline$L V O L$ & $\begin{array}{l}0.127 \\
2.06\end{array}$ & $\begin{array}{l}0.074 \\
1.39\end{array}$ & $\begin{array}{l}0.111 \\
1.47\end{array}$ & $\begin{array}{l}0.197 \\
2.20\end{array}$ & $\begin{array}{l}0.222 \\
2.19\end{array}$ & $\begin{array}{l}0.395 \\
3.18\end{array}$ \\
\hline$?$ & $\begin{array}{l}-0.036 \\
-0.17\end{array}$ & $\begin{array}{l}-1.122 \\
-4.44\end{array}$ & $\begin{array}{l}-1.068 \\
-2.89\end{array}$ & $\begin{array}{l}-0.718 \\
-1.36\end{array}$ & $\begin{array}{l}-0.073 \\
-0.13\end{array}$ & $\begin{array}{l}-0.007 \\
-0.00\end{array}$ \\
\hline $\begin{array}{l}\mathbf{R}^{2} \\
\mathbf{N}(\mathbf{o b s})\end{array}$ & $\begin{array}{l}30.4 \% \\
226\end{array}$ & $\begin{array}{l}39.6 \% \\
241\end{array}$ & $\begin{array}{l}30.5 \% \\
234\end{array}$ & $\begin{array}{l}26.0 \% \\
230\end{array}$ & $\begin{array}{l}15.6 \% \\
217\end{array}$ & $\begin{array}{l}17.8 \% \\
175\end{array}$ \\
\hline
\end{tabular}

Panel B: $\quad$ Average Specialness (in percent)

\begin{tabular}{l|lccccc} 
& Day 1 & Day 5 & Day 10 & Day 15 & Day 20 & Day 25 \\
\hline Observable & 2.95 & 2.77 & 2.41 & 2.04 & 1.75 & 1.47 \\
All 311 (est) & 2.96 & 3.17 & 2.85 & 2.36 & 1.84 & 1.46
\end{tabular}




\section{Table V \\ Comparison of IPO Index Returns}

For each trading day $t$ from 10/29/1998 through 10/27/1999 we calculate three equal-weighted averages of returns of IPOs that are six to twelve months post-IPO as of $t$ to the close of $t$ from the close of $t-1$. The specialness of a stock is the value-weighted average shortfall of the rebate rates of all Medium or Large (as categorized by our data provider) loans of the stock from the Medium or Large mode rebates, respectively. A stock is on special if its specialness is at least 25bp. Unconstrained ${ }_{t}$ is the average across all stocks, $G C \&$ Special $_{t}$ is the average across all stocks with Medium or Large loans on $t+2$, and $G C_{-} O n l y_{t}$ is the average across all stocks that have a Medium or Large loan and that are not on special on $t+2$. Regressions of GC\&Special and GC_Only on Unconstrained are in the Panel A, and regressions of ImGC\&Special and ImGC_Only on ImUnconstrained, where Im indicates that each IPO return is subtracted from the return of the appropriate market index: the Internet Index of Ofek and Richardson (2001) for stocks on the list of DotComs in that paper, and the value-weighted CRSP index for all other stocks. T-statistics are below coefficients, in parentheses.

Panel A: $\quad$ Total Index Returns

$\begin{array}{lcll}\text { GC\&Special }_{t} & =-0.0002 & +1.403 \text { Unconstrained }_{t}+e_{t} & \mathrm{R}^{2}=81.8 \% \\ & (-0.41) & (33.5) & \mathrm{N}=251 \\ & & & \\ \text { GC_Only } t & =-0.0003 & +1.357 \text { Unconstrained }_{t}+e_{t} & \mathrm{R}^{2}=77.6 \% \\ & (-0.55) & (29.4) & \mathrm{N}=251\end{array}$

\begin{tabular}{lccl} 
Panel B: & Market-Excess Index Returns & \\
\hline ImGC\&Special $_{t}$ & $=-0.0001$ & +0.793 ImUnconstrained $_{t}+e_{t}$ & $\mathrm{R}^{2}=48.2 \%$ \\
& $(-0.23)$ & $(15.2)$ & $\mathrm{N}=251$ \\
& & & \\
ImGC_Only $_{t}$ & $=-0.0004$ & +0.774 ImUnconstrained & \\
& $(-0.64)$ & $(12.9)$ & $\mathrm{R}^{2}=40.0 \%$
\end{tabular}

Table VI

Lockup-Expiration Trades

Day 0 is the trading day when an IPO's insider lockup expires. For each day in a window around day 0 , an investor shorts the IPO and buys the appropriate index (the Internet index of Ofek and Richardson for IPOs on the DotCom list in that paper, and the value-weighted CRSP index for all other stocks) to the close of the next day if shorting the IPO is possible. The specialness of a stock is the value-weighted average shortfall of the rebate rates of all Medium or Large (as categorized by our data provider) loans of the stock from the Medium or Large mode rebates, respectively. A stock is on special if its specialness is at least 25bp. The Unconstrained investor can short all stocks, the GC\&Specials investor can short stocks with at least one Medium or Large loan three days later, and the GC Only investor can short stocks with Medium or Large loans that are not on special. Mean and $t$-stat are the investor's average return, and the associated t-statistic, across all the IPOs he can short at least one day, $N(o b s)$ is the number of IPOs he shorts, and spec is the average specialness cost (specialness times the number of days over 360) for GC\&Specials. Results for a five-day window around day 0 (hold from -3 to 2 , if possible) are on the left side, and results for a three-day window (hold from -2 to 1 , if possible) are on the right.

\begin{tabular}{|c|c|c|c|c|c|}
\hline & \multicolumn{2}{|c|}{ Day -3 to Day 2} & \multicolumn{3}{|c|}{ Day-2 to Day 1} \\
\hline & Mean $t$-stat & $N(o b s)$ spec & Mean $t$-stat & $N(o b s)$ & spec \\
\hline Unconstrained & $3.09 \% 3.75$ & 226 & $2.13 \% 3.04$ & 229 & \\
\hline GC\&Specials & $4.76 \% 4.22$ & $0.02 \%$ & $4.52 \% 5.04$ & 106 & $0.01 \%$ \\
\hline GC Only & $3.20 \% 2.88$ & 81 & $3.63 \% 4.10$ & 74 & \\
\hline
\end{tabular}




\section{Table VII \\ The Specialness of Merger Acquirers}

This table presents results from a regression of the specialness of merger acquirers on several explanatory variables.

$$
\operatorname{Special}_{t+3}^{\mathrm{A}}=\mathrm{a}+\mathrm{b} \ln \left(\operatorname{Mktcap}^{\mathrm{A}}\right)+\mathrm{c} \ln \left(\mathrm{Mktcap}^{\mathrm{T}}\right)+\varepsilon_{\mathrm{t}}
$$

Special $_{t+3}^{\mathrm{A}}$ is the difference between the rebate on loans of the acquirer on day $t+3$ and the typical rebate on day $t+3 \cdot \ln (\text { Mktcap })^{\mathrm{A}}$ is the natural $\log$ of the market capitalization of the acquirer at the end of the month before the month in which day $t$ falls. $\ln (\text { Mktcap })^{T}$ is the same measure for merger targets. We use mergers announced between October 28, 1998 and September 28, 1999. P-values and parameter estimates are based on the censored regression model.

\begin{tabular}{lccccc}
$\begin{array}{c}\text { Explanatory } \\
\text { Variable }\end{array}$ & $\mathbf{0}$ & \multicolumn{2}{c}{ Trading Days Since Merger Announcement } \\
\hline & & $\mathbf{5}$ & $\mathbf{1 0}$ & $\mathbf{1 5}$ & $\mathbf{2 0}$ \\
\hline \multirow{2}{*}{ Intercept } & 5.6353 & 6.1522 & 4.6545 & 3.8027 & 3.3146 \\
& 0.0030 & 0.0093 & 0.0459 & 0.1849 & 0.2250 \\
& & & & & \\
$\ln \left(\right.$ Mktcap $\left.^{A}\right)$ & -0.6438 & -0.6880 & -0.6585 & -0.4687 & -0.3884 \\
& 0.0005 & 0.0002 & 0.0064 & 0.1318 & 0.2193 \\
$\ln \left(\right.$ Mktcap $\left.^{T}\right)$ & 0.2736 & 0.2759 & 0.3252 & 0.1906 & 0.1297 \\
& 0.1167 & 0.1041 & 0.1502 & 0.4721 & 0.6133
\end{tabular}

Observations

\begin{tabular}{llllll}
\hline Uncensored & 62 & 50 & 53 & 44
\end{tabular}

(Specials)

\begin{tabular}{llllll} 
Total & 226 & 225 & 224 & 224 & 223 \\
\hline
\end{tabular}




\section{Table VIII \\ The Profitability of Merger Arbitrage when Short-Selling is Costly}

We compute returns for a portfolio comprising a long position in the target firm and a short position in the acquiring firm. For the "Unconstrained" portfolio, day $t$ returns for merger position $i$ are $r_{i, t}=r_{T, t}-r_{A, t}$ where $\mathrm{r}_{\mathrm{A}, \mathrm{t}}$ and $\mathrm{r}_{\mathrm{T}, \mathrm{t}}$ are day-t returns on the acquiring and target firms' stocks, respectively. For the " $G C$ \& Specials" portfolio, a merger pair is only included in the feasible portfolio if our database indicates the existence of a medium or large loan in the acquirer's stock on day $t+3$. "GC Only" requires the existence of a medium or large loan in the acquirer's stock on day $\mathrm{t}+3$ with specialness of $0.25 \%$ or less. "Average Daily Difference" is the average of the daily difference between the "Unconstrained" portfolio and the "GC Only" portfolio. The difference is statistically signific ant for "All Mergers" and "Successes" with p-values of $1.35 \%$ and $0.15 \%$, respectively. Portfolio returns do not include returns until two trading days after the announcement. In Panel B, day t returns for merger position i are $r_{i, t}=r_{T, t}$. There are between 7 and 87 merger observations in each day of the "GC \& Specials" portfolio, over which we take the equal-weighted average. In the "Failures" portfolio, there are two days where there are no active deals, so the portfolio return is the federal funds rate. We compute the cumulative return over the 251 trading days between October 28, 1998 and October 26, 1999 period by compounding in the usual way. Sharpe ratios are computed using the average fed-funds rate over the period of 3.47\%. 4-factor alphas are computed with the intercepts from the daily regression: $R_{i}-R_{R F}=a_{i}+b_{i} R M R F+h_{i} H M L+s_{i} S M B+m_{i} M O M+e_{i}$ over the sample period and then annualized for each merger portfolio i (factor construction is described in the fundamentals section of the text). The alpha for the "Average Daily Difference" row is the alpha of a portfolio that is formed by taking the daily difference between "Unconstrained" and "GC Only" portfolios.

\begin{tabular}{llcccc}
\hline Portfolio & & $\begin{array}{l}\text { Return } \\
10 / 28 / 98- \\
10 / 26 / 99\end{array}$ & $\begin{array}{l}\text { Sharpe } \\
\text { Ratio }\end{array}$ & $\begin{array}{l}\text { 4-Factor } \\
\text { Alpha } \\
\text { (Annualized) }\end{array}$ & P-Value \\
Panel A: Long-Short Portfolios & & & & \\
\hline All Mergers & Unconstrained & $64.287 \%$ & 97.531 & $94.733 \%$ & $0.002 \%$ \\
& GC\&Specials & $44.568 \%$ & 58.910 & $58.400 \%$ & $0.806 \%$ \\
& GC Only & $31.127 \%$ & 46.318 & $40.227 \%$ & $2.205 \%$ \\
& Average Daily Difference & $0.090 \% *$ & & $85.456 \%$ & $0.007 \%$ \\
\hline Failures & Unconstrained & $-34.764 \%$ & -11.229 & $-21.993 \%$ & $76.807 \%$ \\
& GC\&Specials & $-46.419 \%$ & -22.390 & $-58.064 \%$ & $11.789 \%$ \\
& GC Only & $-35.595 \%$ & -17.856 & $-45.699 \%$ & $26.240 \%$ \\
& Average Daily Difference & $0.037 \%$ & & $-25.719 \%$ & $72.412 \%$ \\
\hline Successes & Unconstrained & $82.505 \%$ & 120.738 & $119.929 \%$ & $<0.001 \%$ \\
& GC\&Specials & $56.991 \%$ & 73.265 & $76.266 \%$ & $0.189 \%$ \\
& GC Only & $38.859 \%$ & 55.517 & $48.980 \%$ & $1.178 \%$ \\
& Average Daily Difference & $0.109 \% *$ & & $109.455 \%$ & $0.001 \%$ \\
\hline Panel B: Long Only Portfolios & & & & \\
\hline All Mergers & & $99.013 \%$ & 96.421 & $157.036 \%$ & $0.013 \%$ \\
Failures & $-30.875 \%$ & -12.688 & $-25.555 \%$ & $65.787 \%$ \\
Successes & $124.263 \%$ & 118.494 & $198.198 \%$ & 0.002 \\
\hline S\&P 500 & $0.203 \%$ & 14.448 & &
\end{tabular}




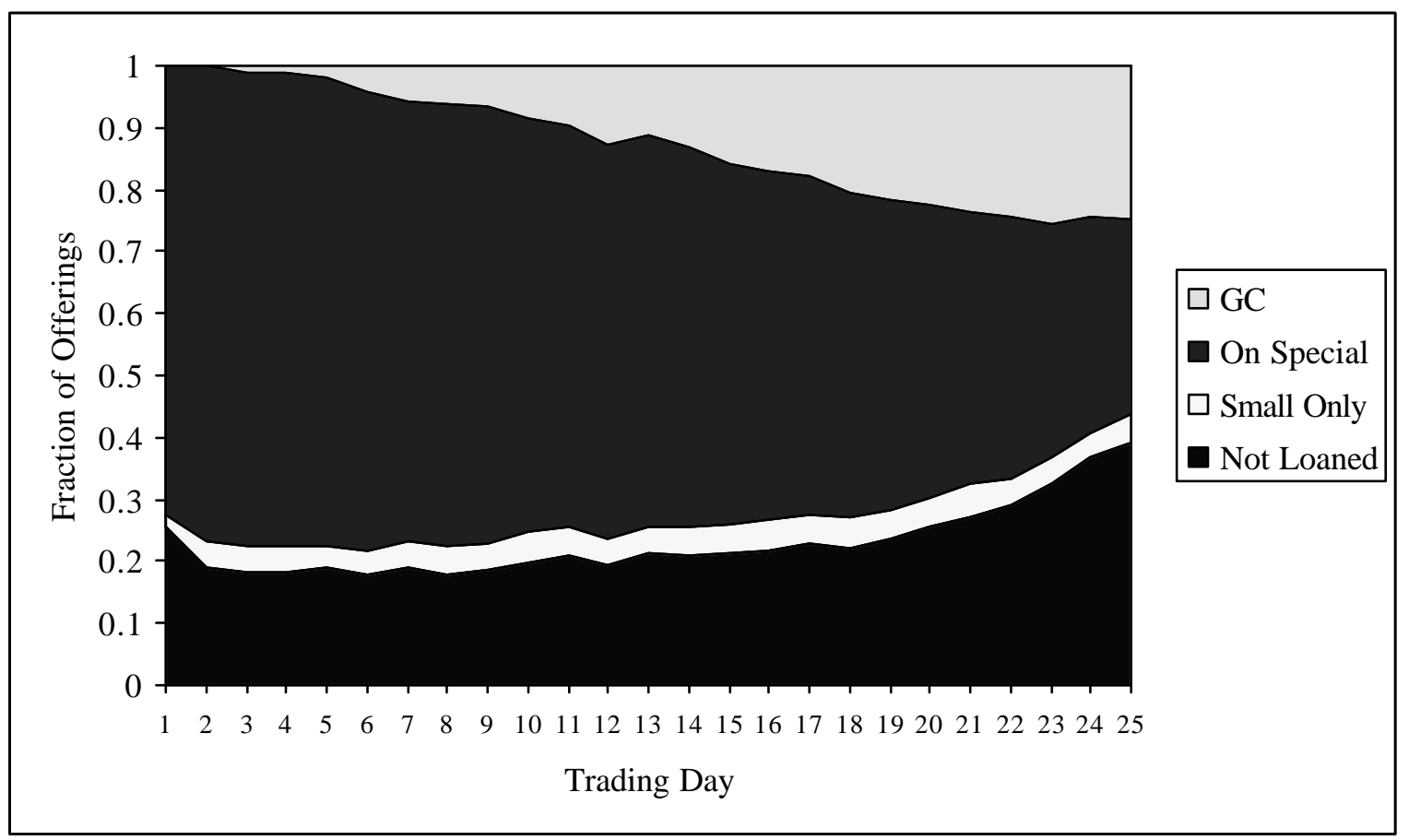

Figure 1. Loan Activity and Status of IPOs in their first 25 trading days.

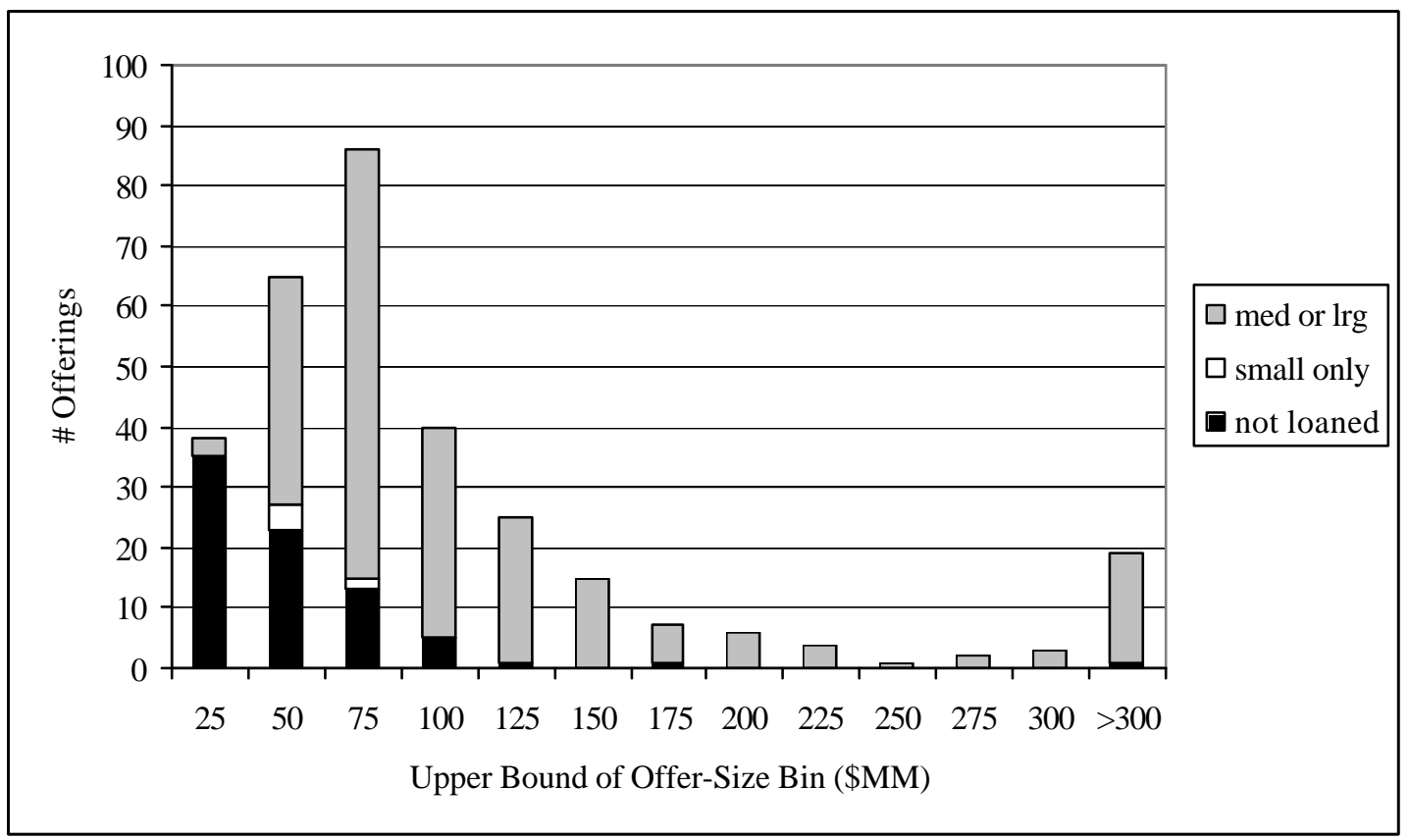

Figure 2. Lending of IPOs on the first settlement day, sorted by IPO offer size. 


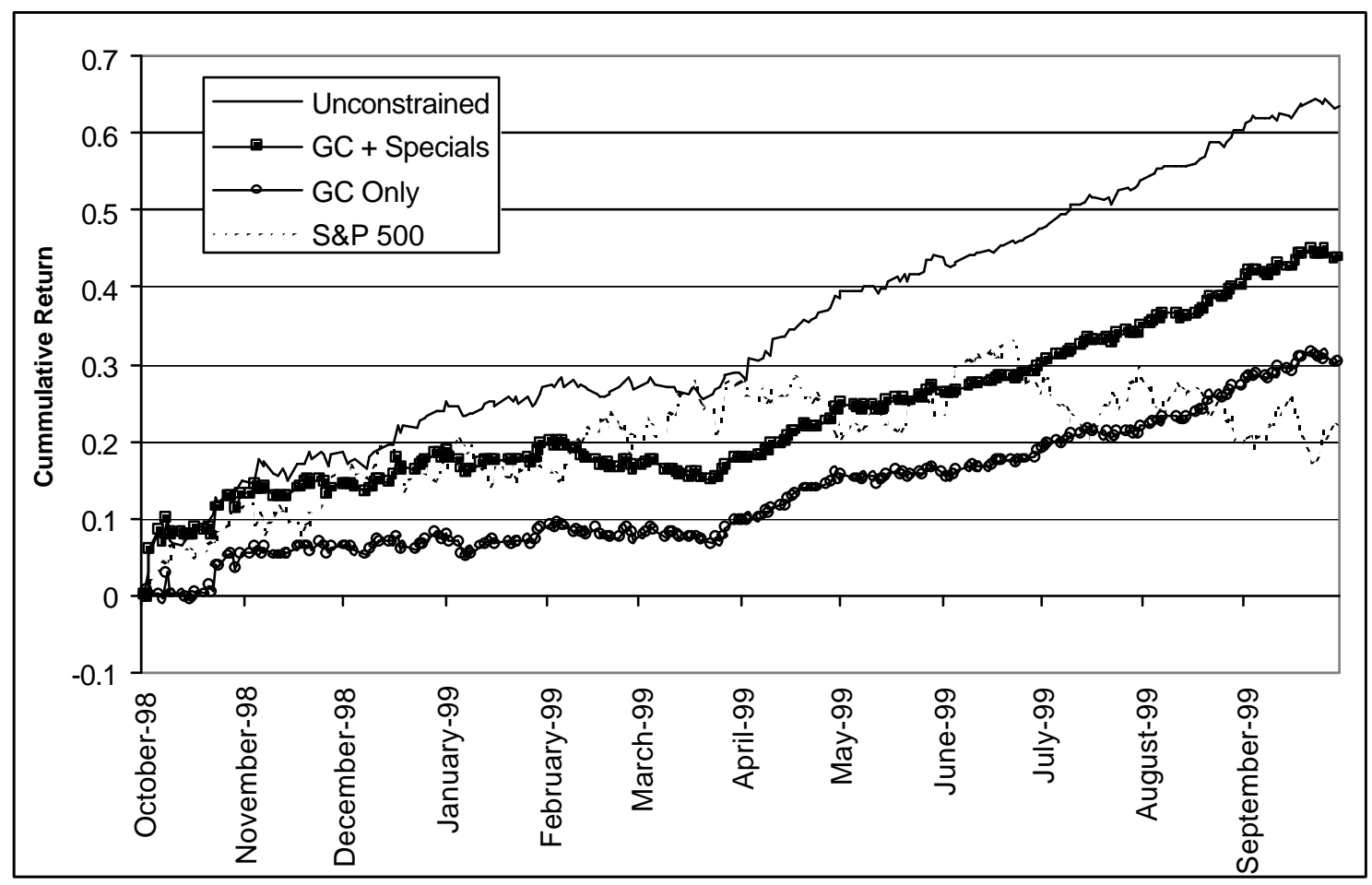

Figure 3. Cumulative Merger Portfolio Returns. We compute returns on a portfolio comprising a long position in the target and a short position in the acquiring firm. For the "Unconstrained" portfolio, day $\mathrm{t}$ returns for merger position $i$ are $r_{i, t}=r_{T, t}-r_{A, t}$ where $r_{A, t}$ and $r_{T, t}$ are day-t returns on the acquiring and target firms' stocks, respectively. For the " $G C+$ Specials" portfolio, day t returns for merger position i are $r_{i, t}=r_{T, t}-r_{A, t}$ where a merger pair is only included in the feasible portfolio if our database indicates the existence of a loan in the acquirer's stock on day $t+3$. "GC Only" requires the existence of a loan in the acquirer's stock on day $t+3$ with specialness of $0.25 \%$ or les s. Portfolio returns do not include mergers until two trading days after the announcement. We compute the cumulative return over the 251 trading days between October 28, 1998 and October 26, 1999. 